\title{
Nucleoside Hydrolase NH 36: A Vital Enzyme for the Leishmania Genus in the Development of T-Cell Epitope Cross-Protective Vaccines
}

OPEN ACCESS

Edited by:

Rashika El Ridi,

Cairo University, Egypt

Reviewed by:

Ramaswamy Kalyanasundaram,

University of Illinois at Chicago,

United States

Héctor Samuel López-Moreno,

Autonomous University of Sinaloa

Mexico

*Correspondence:

Clarisa Beatriz Palatnik-de-Sousa immgcpa@micro.ufr..br

Specialty section:

This article was submitted to Vaccines and Molecular Therapeutics, a section of the journal

Frontiers in Immunology

Received: 11 December 2018 Accepted: 27 March 2019 Published: 16 April 2019

Citation:

Palatnik-de-Sousa CB (2019) Nucleoside Hydrolase NH 36: A Vital Enzyme for the Leishmania Genus in the Development of T-Cell Epitope

Cross-Protective Vaccines.

Front. Immunol. 10:813.

doi: 10.3389/fimmu.2019.00813

\author{
Clarisa Beatriz Palatnik-de-Sousa ${ }^{1,2 *}$ \\ ${ }^{1}$ Institute of Microbiology Paulo de Góes, Federal University of Rio de Janeiro, Rio de Janeiro, Brazil, ${ }^{2}$ Faculty of Medicine, \\ Institute for Research in Immunology, University of São Paulo, São Paulo, Brazil
}

$\mathrm{NH} 36$ is a vital enzyme of the DNA metabolism and a specific target for anti-Leishmania chemotherapy. We developed second-generation vaccines composed of the FML complex or its main native antigen, the NH36 nucleoside hydrolase of Leishmania (L.) donovani and saponin, and a DNA vaccine containing the NH36 gene. All these vaccines were effective in prophylaxis and treatment of mice and dog visceral leishmaniasis $(\mathrm{VL})$. The FML-saponin vaccine became the first licensed veterinary vaccine against leishmaniasis (Leishmune ${ }^{\circledR}$ ) which reduced the incidence of human and canine VL in endemic areas. The NH36, DNA or recombinant protein vaccines induced a Th1 $\mathrm{CD} 4^{+} \mathrm{IFN}-\gamma^{+}$mediated protection in mice. Efficacy against $\mathrm{VL}$ was mediated by a CD4 ${ }^{+}$TNF- $\alpha$ T lymphocyte response against the NH36-F3 domain, while against tegumentary leishmaniasis (TL) a CD8 ${ }^{+} \mathrm{T}$ lymphocyte response to $\mathrm{F} 1$ was also required. These domains were $36-41 \%$ more protective than $\mathrm{NH} 36$, and a recombinant F1F3 chimera was $21 \%$ stronger than the domains, promoting a $99.8 \%$ reduction of the parasite load. We also identified the most immunogenic NH36 domains and epitopes for PBMC of active human VL, cured or asymptomatic and $\mathrm{DTH}^{+}$patients. Currently, the $\mathrm{NH} 36$ subunit recombinant vaccine is turning into a multi-epitope $T$ cell synthetic vaccine against $\mathrm{VL}$ and $\mathrm{TL}$.

Keywords: visceral leishmaniasis vaccines, cutaneous leishmaniasis vaccines, nucleoside hydrolases, multiepitope vaccines, Leishmune ${ }^{\circledR}$ vaccine

\section{INTRODUCTION}

In recent years, nucleoside hydrolases (NHs) of protozoa emerged as strong phylogenetic markers $(1,2)$ and as vital protagonists of pathways for parasite replication (3-5). Moreover, since they are also involved in the establishment of early infection (3-5), they can be considered new targets for drug development (5-8) and excellent candidates for the pathogen recognition by adaptive immune responses (9-15).

Protozoa, fungi and bacteria obtain their purines after the cleavage of exogenous DNA through the enzymatic activity of NHs $(3,16)$. These enzymes, which are crucial for pathogen replication, are expressed in the early stages of infection. In contrast, nucleoside hydrolases are absent from mammal cells, which are capable of synthesize the purines and pyrimidines needed for their own DNA replication (3). Consequently, NHs are excellent targets for selective toxicity against pathogens. 
Additionally, these enzymes, which are expressed at the initial stages of infection of many pathogens, are very immunogenic and share high levels of identity in their amino acid sequences, therefore, generation of protection against them would prevent the early replication of many different microorganism $(13,15$, 16). Hence, vaccines developed against NHs of one pathogen could determine strong protection against infections caused, not only by the homologous strain, but also by different strains or by pathogens of other related or non-related taxonomic groups (9-14). In this sense, NHs become excellent candidates for the development of universal vaccines, which are considered one of the highest priorities for the effective control of epidemics.

In this review, we will discuss the potential use of NHs as targets of the chemotherapy against leishmaniasis. Furthermore, we will consider the use of immucillins, which are synthetic analogs of nucleosides that inhibit the enzymatic function of NHs and cure leishmaniasis through a bivalent effect: the direct toxicity against the Leishmania parasites and the stimulation of a Th1 immune response of the host. Additionally, we will show that the main antigen of the first licensed anti-Leishmania vaccine called Leishmune ${ }^{\circledR}$ (17-22), is a NH (23) that evolved to a DNA (24) and recombinant protein vaccine. $\mathrm{NH}$ is now the focus of the development of a synthetic multiepitope T-cell vaccine against leishmaniasis (10-14).

\section{NUCLEOSIDE HYDROLASES ARE KEY ENZYMES FOR THE REPLICATION OF PARASITIC PROTOZOA, YEAST AND BACTERIA}

To establish an infection in human and mammal reservoirs, pathogens must be able to synthesize their own DNA efficiently and replicate intensively. Mammal cells use the de novo pathway to obtain purines (16) in their purinosomes (25). In contrast, fungi, bacteria (16), and parasitic protozoa like Plasmodium (26, 27), Entamoeba hystolytica (28, 29), Giardia lamblia (30), Toxoplasma gondii $(31,32)$, Trichomonas vaginalis (33), Trypanosoma cruzi (34), Trypanosoma brucei (35-37), and Leishmania (38, 39), are purine auxotrophs, which lack the de novo metabolic route and obtain their purines and pyrimidines from imported DNA through salvage pathways.

All these pathogens import DNA from exogenous sources and nucleotidases/nucleases release nucleotides at the level of the plasma membrane. These nucleotides are de-phosphorylated and transported into cells as nucleosides (40). Alternatively, nucleosides are carried into cells by specific transporters (41). Once inside the cells, nucleoside hydrolases (39) or nucleoside phosphorylases (PNP) (42) in the cytoplasm, release the purines from the nucleosides, which can further be used by the pathogen for the synthesis of its DNA.

Since the enzymatic function of NHs is so mandatory for pathogens and because they are absent from mammals cells, they become excellent targets for selective chemotherapy.

\section{NUCLEOSIDE HYDROLASES ARE PHYLOGENETIC MARKERS OF THE LEISHMANIA GENUS}

As expected for their essential role in the replication of intracellular parasites, NHs are present in all the studied species of the Leishmania genus $(13,15,39,43,44)$. In fact, NHs that share high levels of homology in their amino acid sequences to NH36 have been described in $L$. (L.) major (95-96\%), $L$. (L.) mexicana (93\%), L. (L.) infantum chagasi (99\%), L. (L.) infantum (99\%), L. (L.) tropica (97\%), L. (V.) braziliensis (84\%), L. (L.) amazonensis (93\%), L. (V.) guyanensis (84\%), and L. (L.) aethiopica $(30 \%)(12,13,15,43,44)$. This high level of identity justifies that fact that these enzymes are considered very relevant as taxonomic and phylogenetic markers of the genus Leishmania. Accordingly, two nucleoside hydrolases were chosen, together with three other metabolic enzymes, as the basis of a profound analysis of the taxonomy and phylogeny of the $L$. (L.) donovani complex. This analysis was performed using multilocus sequence typing (2). These enzymes are dimeric and encoded by a single gene. Actually, the presence of $\mathrm{NH} 1$ and $\mathrm{NH} 2$ was confirmed in 17 isolates of L. (L.) infantum and in 20 strains of $L$. (L.) donovani from the World Health Organization Bank. Confirming their status as conservative markers of the Leishmania genus, the $\mathrm{NH} 1$ and $\mathrm{NH} 2$ genes were expressed by the 1-2 allele forms in the strains of $L$. (L.) infantum and by the 3-6 alleles in the strains of $L$. (L.) donovani (2).

\section{NUCLEOSIDE HYDROLASES ARE TARGETS OF CHEMOTHERAPEUTIC NUCLEOSIDE ANALOGS}

NHs are attractive targets for the chemotherapy of leishmaniasis. The inhibition of the enzymatic functions of NHs would impair the parasite growth with no damage to the mammal host cells. In a recent work we investigated the potential inhibitory action of synthetic nucleoside analogs called immucillins on Leishmania replication in vitro and on the enzymatic function of the nucleoside hydrolase of Leishmania (L.) donovani NH36 (5).

Immucillins are synthetic deazapurine iminoribitols which have been described as inhibitors of the in vitro activity of the nucleoside hydrolases of Crithidia fasciculata (39), Leishmania (L.) major (39), and Trypanosoma brucei brucei (36); however, with no record of anti-parasite activity. Lately, second and third generation immucillins showed inhibitory activity against PNP (45) and were chemotherapeutic against malaria of monkeys infected with Plasmodium falciparum (26).

We recently demonstrated that $\mathrm{NH} 36$ of $L$ (L.) donovani is a non-specific nucleoside hydrolase, which has adenosine and inosine as favored substrates and develops good catalytic activity against uridine and cytidine pyrimidine nucleosides (5). L. (L.) donovani parasites cease to grow after purine starvation, but for adaptation purposes cells suffer a proteome re-modeling and they upregulate purine transport, salvage of purines metabolism and their correspondent proteins (46). The proteomes of purine-starved and purine repleted parasites 
were recently compared. After $48 \mathrm{~h}$ of purine starvation, the expression of the purine-specific nucleoside hydrolase (putative inosine-adenosine-guanosine-nucleoside hydrolase IAGNH, LinJ.292910) and the 6-hydroxipurine nucleoside hydrolase (inosine-guanosine-nucleoside hydrolase, IGNH, LinJ.14.0130) were enhanced. In contrast, the non-specific NH (LinJ178.1570) showed no significant change or even a decreased expression (46).

Inhibition of the replication of promastigotes of $L$. (L.) infantum chagasi and $L$. (L.) amazonensis in vitro was achieved after co-incubation with the first generation Immucilin A (IA) and Immuclin $\mathrm{H}(\mathrm{IH})$, second-generation DadME-Immucilin $\mathrm{H}$ (DIH) and fourth generation SerMe-Immucilin $\mathrm{H}$ (SMIH), SerMe-Immucilin G (SMIG), and SerMe-Immucilin A (SMIA), at nanomolar to micromolar concentrations (5). Their efficacies on both species of Leishmania were similar, but DadMEImmucilin G (DIG) was more potent to inhibit L. (L.) infantum chagasi, and SMIA against L. (L.) amazonensis. IA, IH and SMIH were the most potent growth inhibitors of both parasites (5). Additionally, we proved that IA, which is a synthetic analog of adenosine, inhibited the Leishmania replication in a chemically defined medium deprived of nucleosides sources, and that the addition of adenosine reverted this effect (5).

Furthermore, we demonstrated that the inhibition of Leishmania replication by treatment with IA and IH was mediated by the inhibition of the NH36 enzymatic activity (5). In addition, both immucillins and SMIH also inhibited the replication of intracellular amastigotes of $L$. (L.) infantum chagasi causing no damage to the macrophage host cells. Additionally, the treatment with IA and IH promoted the swelling and morphological alteration of promastigotes while SMIH caused intense vacuolization and kinetoplast damage (5).

Our results confirmed that NH36 is a vital enzyme for Leishmania replication and therefore, it is reasonable to assume that it is also, an excellent target for save chemotherapy against leishmaniasis.

\section{DRUGS THAT TARGET NUCLEOSIDE HYDROLASES ARE ALSO IMMUNOGENIC}

The in vivo chemotherapeutic potential of the IA, IH and SMIH immucillins was further assayed in BALB/c mice infected with $L$. (L.) infantum chagasi amastigotes and compared with that of the golden standard drug Glucantime ${ }^{\circledR}$ (6). Visceral leishmaniasis is a chronic and frequently lethal protozoan disease against which no human vaccine is available and current treatment is reduced to a few highly toxic drugs administered intravenously, thus requiring hospitalization.

Among the immucillins, IA induced the strongest reduction of parasite load (89\%), followed by $\mathrm{IH}(85 \%)$ and SMIH (85\%). Treatment with immucillins also determined high titers of anti-NH36 IgG2a antibodies and a gain in corporal weight, further the immucillins prevented the weight increase in the liver and spleen detected in infected controls, which exhibited the highest IgG1 anti-NH36 response (6). All immucillins, most notably IA, promoted in splenocytes a higher secretion of IFN- $\gamma$ and TNF- $\alpha$ to the supernatants than the infected controls. In contrast, the IL-10 secretion was observed mainly in the infected untreated controls.

This remarkable significant increase of secretion from the pro-inflammatory cytokines after immucillin treatment could be due to the killing of parasites and the recovery of the Th1 immune response of the host, or to a direct immunogenic effect of the drugs. Therefore, to clarify this question we treated normal uninfected mice and observed that the secretion of IFN- $\gamma$ and TNF- $\alpha$ from splenocytes, in response to NH36, was enhanced more after therapy with immucillins than with Glucantime ${ }^{\circledR}$, which in contrast increased the IL-10 secretion. In addition, IA increased the frequencies of $\mathrm{CD} 4^{+} \mathrm{T}$ and $\mathrm{CD} 19^{+} \mathrm{B}$ lymphocytes, while SMIH increased only the $\mathrm{CD}_{19}{ }^{+} \mathrm{B}$ cells counts (6). The IA and IH immucillins were also therapeutic in $L$. (L.) infantum chagasi infected mice and hamsters showing no toxicity. In contrast, the treatment with Glucantime ${ }^{\circledR}$ promoted high levels of urea, creatinine, aspartate aminotransferase (GOT) and alanine aminotransferase (GPT) in mice. These experimental data indicated that IA induced the strongest therapeutic effect on visceral leishmaniasis probably through the combined toxicity against the parasite and the induction of a Th1 immune response of the host (6).

\section{THE NH36 OF LEISHMANIA (L.) DONOVANI IS THE MAIN ANTIGEN OF THE SECOND-GENERATION LEISHMUNE ${ }^{\circledR}$ VACCINE}

Visceral leishmaniasis is a highly endemic and epidemic protozoan vector-borne disease which causes 400,000 new annual cases and it is frequently lethal if untreated soon after the onset of symptoms. Only a few drugs are used for the chemotherapy, which is still highly toxic. Therefore, the development of a preventive specific vaccine for the epidemiological control of $\mathrm{VL}$ is considered urgent (47). VL is a human anthroponosis caused by $L$. (L.) donovani in India, Asia and East Africa, and a canid zoonosis caused by $L$. (L.) infantum chagasi in the Americas and by $L$. (L.) infantum in the Middle East, Central Asia, China and the Mediterranean (48). Ninety percent of the world incidence of the disease is concentrated in Bangladesh, India, Nepal, Sudan, Ethiopia and Brazil. Although four vaccines against canine VL have already been licensed (Leishmune ${ }^{\circledR}(17-22)$, Leishtec ${ }^{\circledR}$ (49), CaniLeish ${ }^{\circledR}(50)$, and Letifend ${ }^{\circledR}$ (51), no vaccine against the human disease is yet available.

In the search for the most immunogenic fraction of the promastigotes of $L$. (L.) donovani (Sudan), we described, in the 80 's, the Fucose Mannose Ligand (FML), which is composed of several protein bands and inhibited in vitro the penetration of promastigotes (52) and amastigotes into the macrophage host cells (53) in a species-specific manner (54). The FML is strongly immunogenic and antigenic in mice and rabbits and most of the monoclonal antibodies raised against it react with its 36 $\mathrm{kDa}$ glycoproteic component (53). The FML was used with success in the specific serodiagnosis of human (55) and dogs 
(56) with visceral leishmaniasis, and for VL control of blood transfusion (57) and, together with its $36 \mathrm{kDa}$ component (58), induced an effective protective vaccination in mice and hamsters against $L$. (L.) donovani infection (59, 60). Saponins, mainly those of Quillaja saponaria Molina, showed the best performance as adjuvants of these vaccine formulations $(61,62)$. The FMLsaponin vaccine induced strong prophylactic protection in a Phase II trial performed on dogs challenged with $L$. (L.) donovani (21), and in two Phase III trials in endemic areas of Brazil, where it showed $76-80 \%$ of vaccine efficacy $(21,63,64)$. These field trials were performed in an area of high infective pressure, where cases of VL were considered animals that died of the disease, or that exhibited symptoms of VL and had parasitological confirmation. The vaccine promoted strong increases of antiFML antibodies $(63,64)$, mainly of the IgG2 subtype (65) and intradermal reaction of the $L$. (L.) donovani promastigote antigen, while significantly reduced the number of deaths, as well as the clinical and parasitological sings of the disease $(63,64)$. In fact, protection lasted for at least 3.5 years (64).

The FML-saponin vaccine, formulated with an increased dosage of adjuvant, was also effective in the therapy of canine visceral leishmaniasis in endemic areas (66). After immunotherapy, no deaths were registered among infected and treated dogs. These animals showed increased anti-FML IgG2 titers and higher percent of positive intradermal response to the leishmanial lysate (IDR) and reduced symptomatology. Furthermore, their normal proportions of $\mathrm{CD} 4^{+} \mathrm{T}$ lymphocytes and $\mathrm{CD} 21^{+} \mathrm{B}$ lymphocytes, suggested their non-infectious condition. Also, their percentages of $\mathrm{CD}^{+} \mathrm{T}$ cells increased, as was expected after treatment with Quillaja saponaria saponin (66).

After that investigation, the FML-saponin vaccine started to be manufactured by Fort-Dodge-Pfizer-Zoetis, and was licensed in Brazil in 2003, as the first worldwide anti-Leishmania vaccine, called Leishmune ${ }^{\circledR}$ (21). The immunogenicity of Leishmune ${ }^{\circledR}$ was proven in 550 dogs of seven Brazilian towns in endemic areas (17). The vaccine showed to be safe (18), sustained the immunogenicity described for the FML-saponin formulation, and promoted a high anti-FML antibody and IDR response, with increased frequencies of $\mathrm{CD}^{+}$and $\mathrm{CD} 21^{+} \mathrm{T}$ cells, and sustained levels of $\mathrm{CD} 4^{+} \mathrm{T}$ cells. Leishmune ${ }^{\circledR}$ also determined a reduction in the number of deaths and symptoms (17). The vaccine was further useful in the therapy of experimental (67) and naturally acquired (68) visceral leishmaniasis. It reduced deaths and determined the clinical and parasitological cure of VL. In addition, PCR analysis revealed that a combined treatment with the vaccine and Amphotericin was necessary to achieve the sterile cure (68). Since then, many investigations disclosed the higher efficacy of Leishmune ${ }^{\circledR}$ to Leishtec ${ }^{\circledR}$ and/ or LBsap vaccines (69, 70 ), its stronger immunogencity and pro-inflammatory response (71-73) and its capability of raising the frequencies of CD8 T cells secreting-IFN- $\gamma$ (74).

This is an inherent property of the Quillaja saponaria adjuvant QS21, which composes the vaccine (75). QS21 saponin is a composed by a triterpene nucleus to which one glycidic moiety is attached to C-3 and a combined glycidic and normonoterpene moiety is attached to C-28. The normonoterpene moiety has been associated to the promotion of a cytotoxic CD8- T cell response (75). Additionally, QS21 has an aldehyde attached to C4, which is involved in the triggering of the Th1 response (75).

Healthy dogs vaccinated with Leishmune ${ }^{\circledR}$ and exposed in endemic areas showed increased antibody and IDR responses but reduced mortality compared to unvaccinated controls (17). Remarkably, dogs vaccinated with Leishmune ${ }^{\circledR}$ not only offer fewer parasites (19) but also, their anti-FML antibodies block the further development of the parasite inside the guts of the to the insect vector $(20,21)$. These two effects combined defined Leishmune ${ }^{\circledR}$ as a transmission blocking vaccine $(20,21)$ and this explains why it reduces the incidence of both, the canine and human diseases as predicted (76) interrupting the epidemics (22). The decreased offer of parasites to sand fly vectors showed in vaccinated dogs, is associated to the absence of Leishmania antigen in skin, and DNA, in blood and lymph nodes (19).

In addition, regarding the Leishmune ${ }^{\circledR}$ vaccine, the western blot analysis of the FML antigen disclosed that the $36 \mathrm{KDa}$ component was specifically recognized by the sera of human patients of VL (77) and it was therefore, the main antigen of the Leishmune ${ }^{\circledR}$. The molecular cloning of the $36 \mathrm{kDa}$ protein identified that it is a nucleoside hydrolase of L. (L.) donovani, which we denominated NH36 (23).

Leishmune ${ }^{\circledR}$ was the first licensed vaccine against canine leishmaniasis. Its license was obtained in Brazil in 2003 (19-22). The current other three commercial vaccines: Leishtec ${ }^{\circledR}$ (49), Canileish ${ }^{\circledR}$ (50), and Latifend (51) were licensed after Leishmune ${ }^{\circledR}$ but also use as adjuvants, saponins of Quillaja saponaria.

Leish-Tec ${ }^{\circledR}$, contains the recombinant protein A2 of amastigotes of $L$. (L.) donovani and showed to be protective against VL in assays with experimental challenges in the mice (78-80), Rhesus monkeys (81), and beagle dog models (82). The license for commercialization of the Leishtec ${ }^{\circledR}$ vaccine was approved in 2008. The first field trial assay of Leishtec ${ }^{\circledR}$, was published in 2016 and was performed in an area of low infective pressure (49). In this area, cases of VL where defined, not by deaths or clinical symptoms with parasite confirmations, as it was used for the Leishmune ${ }^{\circledR}$ vaccine $(21,63,64)$, but, instead, by seropositivity confirmed by at least one of three parasitological assays, or by adding xenodiagnoses to parasite assays (49). Using these less severe criteria, the authors reported $71.4 \%$ vaccine efficacy, based on the parasitological definition of cases and $58.1 \%$, by adding xenodiagnoses (49). In agreement with that, when a field trial of Leishtec ${ }^{\circledR}$ was performed in a high infective pressure area, a lower reduction in the rate of canine infection was observed (83). In fact, the incidence of VL was $42 \%$ in controls and $27 \%$ in vaccinated dogs, representing only a $35.7 \%$ of vaccine efficacy (83). In addition, protective responses were either, not generated or not maintained, in $43 \%$ of the immunized dogs that became infected and developed disease overtime. Furthermore, the levels of anti-A2 specific IgG antibodies were significantly higher in vaccine recipients than in infected control dogs confirming the immunogenicity of A2 (83).

Furthermore, a recombinant protein, named Q formed by the genetic fusion of five intracellular antigenic fragments, from the L. (L.) infantum acidic ribosomal proteins Lip2a, Lip2b, P0, and 
histone $\mathrm{H} 2 \mathrm{~A}(51,84)$ was licensed as the Letifend ${ }^{\circledR}$ vaccine. In a recent field trial in France and Spain, the definition of a case included clinical signs confirmed by positive Elisa and the finding of parasites in bone marrow or lymph nodes through PCR or microscopic observation of smears. Based on these results the vaccine efficacy was $72 \%$ (84).

Finally, the CaniLeish ${ }^{\circledR}$ vaccine is composed of the Leishmania (L.) infantum Excreted Secreted Proteins (ESP) and the Purified extract of Quillaja saponaria (QA-21) also showed Th1 dominated immune response which persisted for a full year (85). A field trial performed in high endemic areas of the Mediterranean basin used PCR and parasite cultures for confirmation of infection (50). Considering the active infection, a $63 \%$ of vaccine efficacy was observed on month 24 after vaccination. Considering the VL symptoms, the vaccine efficacy was $68.4 \%$ (86). In agreement, it has been acknowledged that only two vaccines, consisting of parasite purified fractions with saponin derivative adjuvants, showed to confer significant protection against disease and death under natural conditions, the FML-QuilA (Leishmune ${ }^{\circledR}$ ) in Brazil, and LiESP/QA-21 $\left(\right.$ CaniLeish $\left.^{\circledR}\right)$ in Europe (85).

\section{NHS PROTEIN SEQUENCES ARE VERY IMMUNOGENIC}

Visceral leishmaniasis is characterized by fever, malaise, anemia, leukopenia, thrombocytopenia, hepatosplenomegaly, hypergammaglobulinemia, and a strong suppression of the cellular immune response (47), mainly due to an intense decrease of the $\mathrm{CD} 4{ }^{+} \mathrm{T}$ helper lymphocyte population, which is responsible for the resistance to the infection $(86,87)$. Therefore, an effective vaccine against VL is expected to guarantee a robust Th1 $\mathrm{CD}^{+} \mathrm{T}$ cell response against the parasite infection, characterized by secretion of IL-12 by antigen-presenting cells (APCs) which promotes the increase of IFN- $\gamma$-secreting Th1 T cells $(86,88)$. The achievement of protection or natural resistance against VL in fact requires the induction of powerful and long-lasting Th1 parasite-specific memory responses, with multifunctional CD4 ${ }^{+}$T cells producing IFN- $\gamma$, IL-2, and TNF- $\alpha$ (10-12, 15, 89). Besides, a balance between the Th1 IFN- $\gamma$ and TNF- $\alpha$ cytokines, the secretion of IL-17 and the regulatory cytokine IL-10 $(90,91)$ is needed. Furthermore, CD8 ${ }^{+} \mathrm{T}$ cells may contribute by secreting beneficial cytokines or with their cytotoxic activity that release amastigotes to be killed by activated monocytes (92). In fact, CD8 + T cells were recently involved in the cure or pathology of CL (93).

$\mathrm{NH}$ enzymes are not only present in many bacteria, fungi and parasitic protozoa species $(2,13,16,43,44)$, in which they are expressed at early stages of infection, but they are also very immunogenic. Interestingly, NH36 is the object of many vaccine studies since it is very antigenic and immunogenic $(9-15,94,95)$. These properties are based on the amino acid composition of the most immunogenic region of the NHs. Aromatic amino acids like phenyl-alanin, tryptophan and tyrosine, together with the hydrophobic amino acids leucine, isoleucine and valine, are common component of the epitopes for MHC Class I receptors on APCs (96). Phenyl-alanin and tryptophan have lateral chains, which make it easier to establish contact with the $\mathrm{T}$ cell receptors (97). In addition, epitopes for the MHC Class II receptors show hydrophobic residues in position 1 and 9, acidic amino acids in position 4 and basic charged amino acids in position 6 (97). Therefore, higher frequencies of hydrophobic, acidic and charged amino acids are expected to be found in the most immunogenic regions of antigens, which are enriched in $\mathrm{T}$ cell epitopes. In agreement to that, the NHs of $L$. (L.) donovani NH36, L. (L.) amazonensis, and $L$. (V.) braziliensis contain a total of 71.1, 74.1 , and $71.7 \%$ of hydrophobic, charged and acidic amino acids, respectively (Table 1), which makes it reasonable to assume that they would constitute good vaccine antigens to promote the $\mathrm{T}$ cell immune response against the parasite.

\section{DEVELOPMENT OF THE NH36 VACCINE AGAINST LEISHMANIASIS: A THIRD-GENERATION VACCINE}

Initially we studied the efficacy of a DNA vaccine containing the NH36 gene cloned in the VR1012 plasmid (24). Using a mice model we compared the efficacy of the FML and the NH36 recombinant protein ( $\mathrm{rNH} 36)$ formulated with saponin with that of the NH36 DNA vaccine, against visceral leishmaniasis due to L. (L.) infantum chagasi, and cutaneous leishmaniasis due to $L$. (L.) mexicana (24). The three vaccines induced the production of IgG, IgG1, and IG2a antibodies and strong IDR against $L$. (L.) infantum chagasi. The rNH36 and FML vaccine also induced enhanced IDR in mice challenged with $L$. (L.) mexicana (24).

FML and $\mathrm{rNH} 36$ showed efficacy of $79 \%$ in reduction of the L. (L.) infantum chagasi parasite load. In contrast, the VR1012-NH36 DNA vaccine was stronger and reduced the $L$. (L.) infantum chagasi parasite load by $88 \%$ and the lesion sizes by induced by $L$. (L.) mexicana (24) and $L$. (L.) amazonensis (98) by 65 and $80.4 \%$, respectively. Remarkably, the DNA vaccine increased the frequencies of INF- $\gamma$ producing $\mathrm{CD}^{+} \mathrm{T}$ cells, triggering a Th1 type immune response against NH36 (24). Our results therefore, indicated that the NH36 DNA vaccine was a very good candidate for the generation of a Th1 immune protection against several Leishmania species (24). In fact, this vaccine was also efficient in the immunotherapy against visceral leishmaniasis of mice (99).

In agreement with the results obtained with mice, the VR1012NH36 vaccine was used with success in prophylaxis (100) and immunotherapy of dogs infected with L. (L.) infantum chagasi (101). Infected dogs treated with the DNA vaccine exhibited increased sizes and proportions of IDR and frequencies of NH36-specific CD4 ${ }^{+} \mathrm{T}$ cell in blood. These lymphocytes recognized mainly the C-terminal peptide of $\mathrm{NH} 36$. On the other hand, the N-terminal of NH36 was the target of the IgG2/IgG1 enhanced antibody ratios and $\mathrm{CD}^{+} \mathrm{T}$ cell counts. Moreover, the immunotherapy with the NH36 DNA vaccine reduced the parasite load in the livers and the loss of body weight of dogs as well, increasing their survival time (101). 
TABLE 1 | Percent of acidic, charged and hydrophobic amino acids of Nucleoside hydrolases of Leishmania.

\begin{tabular}{|c|c|c|c|c|}
\hline Groups & Amino acids & L. (L.) donovani NH36 AAG02281.1 & L. (L.) amazonensis NH A34880 & L. (V.) braziliensis NH XP 1564081 \\
\hline \multirow[t]{2}{*}{ Acidic } & Glu & 5.1 & 7.2 & 6.4 \\
\hline & Asp & 6.1 & 6.3 & 5.4 \\
\hline Charged & Arg & 5.1 & 3.0 & 4.8 \\
\hline \multirow[t]{6}{*}{ Hydrophobic } & Ala & 9.2 & 12.0 & 8.7 \\
\hline & lle & 6.1 & 4.5 & 7.7 \\
\hline & Pro & 6.4 & 5.1 & 6.4 \\
\hline & Phe & 3.2 & 3.9 & 2.6 \\
\hline & $\operatorname{Trp}$ & 0.6 & 2.4 & 0.6 \\
\hline & Cys & 1.6 & 3.6 & 2.2 \\
\hline
\end{tabular}

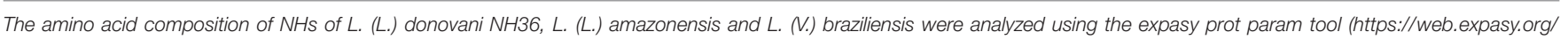
protparam/).

\section{SEARCHING FOR THE MOST IMMUNOGENIC DOMAINS OF NH36}

Previous concerns existed about the usage of short sequences of a protein antigen in a vaccine. In comparison to native antigens that contain PAMPs as their natural adjuvants, the recombinant proteins would be not immunogenic as they are purified and are free from PAMPs (102). Moreover, there was a general consensus that recombinant subunits would probably not retain the immunogenicity inherent to the whole protein. However, recent evidence has demonstrated that protein domains of a vaccine candidate, that concentrate its most immunogenic amino acid sequences, might impair and even exceed the protective response induced by the whole molecule (103).

Aiming to identify the most immunogenic domains of NH36, we first subcloned the NH36, which is composed of 314 amino acids, into three recombinant peptides covering all its sequence: the N-terminal, F1 (amino acids 1-103), the Central domain, F2 (amino acids 104-198), and the C-terminal domain, F3 (amino acids 198-314) in the pET28b expression system. We vaccinated mice with the NH36, or each one of the peptides and saponin and challenged them with $L$. (L.) infantum chagasi or $L$. (L.) amazonensis (9).

Thus, we described for the first time the role of the nucleoside hydrolases in the induction of immunoprotective $\mathrm{CD} 4^{+} \mathrm{T}$ cell driven or $\mathrm{CD}^{+} \mathrm{T}$ cell-mediated cytotoxic immune response, in the mouse model of visceral and cutaneous leishmaniasis (9). We identified that, in the mice challenged with $L$. (L.) infantum chagasi, the adaptive immune response of mice is directed against the F3 domain and is mainly mediated by $\mathrm{CD} 4^{+} \mathrm{T}$ cells with a minor contribution of $\mathrm{CD}^{+} \mathrm{T}$ cells (9). Actually, immunization with the F3 peptide exceeded the protective efficacy promoted by the cognate NH36 protein by $36 \%(9,103)$. The increases in DTH and TNF- $\alpha / \mathrm{IL}-10$ ratios were the strong correlates of protection in the F3-vaccinated mice, and were negatively associated to the $88-90 \%$ of reduction of the parasite load. Additionally, increases in IgG1 and IgG2 anti-NH36 antibodies, CD4 ${ }^{+} \mathrm{T}$ cell proportions, secretion of IFN- $\gamma$, ratios of IFN- $\gamma /$ IL- 10 producing $\mathrm{CD}^{+}{ }^{+}$and $\mathrm{CD}^{+}{ }^{+} \mathrm{T}$ cells and percentages of inhibition of binding of anti-NH36 antibodies to predicted epitopes were also detected, in mice vaccinated with F3. Vaccination with the F1 peptide, on the other hand, although induced an immune response, did not show any impact on the L. (L.) infantum chagasi parasite load (9).

In contrast, both the F1 and F3 domains reduced the size of footpad lesions of vaccinated mice infected with $L$. (L.) amazonensis (9). Our results therefore suggested that the domains of NH36 could be the basis for the development of a bivalent vaccine against visceral and cutaneous leishmaniasis (9). Both F1 and F3 vaccines enhanced the IgG and IgG2a antibodies and the F3 promoted the strongest DTH and the highest proportions of $\mathrm{CD}^{+}$and $\mathrm{CD}^{+}{ }^{+} \mathrm{NH} 36$-specific $\mathrm{T}$ cells and secretion of IFN- $\gamma$ and TNF- $\alpha$. According to experiments of depletion with monoclonal antibodies, the cross-efficacy against the infection by L. (L.) amazonensis is based on a CD4 ${ }^{+} \mathrm{T}$ celldriven response against the $\mathrm{C}$-terminal domain that determines a $75 \%$ reduction of the lesion sizes, and on a $\mathrm{CD}^{+} \mathrm{T}$ cell response against the $\mathrm{N}$-terminal domain of $\mathrm{NH} 36$, that reduced the lesions by $57 \%$ (10). The F3 alone (9) or together with the F1 vaccine $(9,10)$ induced durable protection against visceral and cutaneous leishmaniasis, respectively, in the mice model. This cross-protection was explained by the $93 \%$ of homology between the amino acid sequence of $L$. (L.) donovani NH36 and the NH A34480 of L. (L.) amazonensis (10). Both shared conserved predicted epitopes for $\mathrm{CD}^{+}{ }^{+}$and $\mathrm{CD} 8^{+} \mathrm{T}$ cells in the $\mathrm{F} 1$ domain, and of $\mathrm{CD}^{+}$epitopes diverging in only one amino acid, in the $\mathrm{F} 1$ and $\mathrm{F} 3$ domains (10).

The F3 and F1 vaccines were also effective in the immunotherapy of mice infected with L. (L.) amazonensis and reduced the parasite load and the sizes of lesions (11). Interestingly, the strongest antibody and DTH response against 
L. (L.) amazonensis was promoted by the F3 peptide, which also induced a Th1 cytokine response, with increased levels of IFN- $\gamma$ and TNF- $\alpha$ but reduced levels of IL-10. In contrast, the F1 vaccine, induced no DTH and promoted similar IFN- $\gamma$, TNF- $\alpha$ and IL-10 secretion, suggesting the presence of regulatory $\mathrm{T}$ cell epitopes in its sequence (10). In the case of the F3 vaccine, the efficacy advanced as the frequencies of the $\mathrm{CD} 4^{+} \mathrm{T}$ cells changed from single (IL- $2^{+}, \mathrm{IFN}-\gamma^{+}$or TNF- $\left.\alpha^{+}\right)$to double-cytokine secretors (IL- $2^{+}$TNF- $\alpha^{+}$, TNF- $\alpha^{+}$IFN- $\gamma^{+}$, and IL-2 ${ }^{+}$IFN- $\gamma^{+}$). In contrast, the F1 vaccine induced, as described before (10), a main advanced $\mathrm{CD} 8^{+} \mathrm{T}$ cell response that changed qualitatively from single to triple-cytokine secretors (IL-2 ${ }^{+}$TNF- $\alpha^{+}$IFN- $\gamma^{+}$), the cell phenotype involved in memory immune responses (104). Therefore, the cure of cutaneous leishmaniasis depends on the generation of a Th1 response by the $\mathrm{F} 3$ vaccine and a $\mathrm{CD} 8{ }^{+} \mathrm{T}$ cell response, by the $\mathrm{F} 1$ vaccine (11).

\section{OPTIMIZATION OF THE PROPHYLACTIC EFFICACY PRESENTING THE IMMUNOGENIC DOMAINS AS A RECOMBINANT CHIMERA}

The theory that defends the development of T-cell epitope vaccines considers that the whole protein antigen is less potent for vaccination than its fractions that are composed of the relevant immunogenic epitopes $(93,103)$. We have confirmed that for the NH36 vaccine (9-11). These relevant domains would also be more potent than the isolated epitopes. For the optimization of the vaccine efficacy, we should therefore use the domains, either admixed or expressed in tandem as one recombinant chimera. In the case of the chimera, the domains epitopes could be simultaneously presented by the MHC Class II and Class I receptors of a single $\mathrm{APC}$ to $\mathrm{CD}^{+}$and $\mathrm{CD} 8^{+}$lymphocytes, respectively, by cross-presentation. This possibility could also potentiate the vaccine efficacy. Recent investigations pointed out the importance of the promotion of both $\mathrm{CD} 4^{+}$and $\mathrm{CD} 8^{+}$ multifunctional $\mathrm{T}$ cells for protection against leishmaniasis (89, 90, 104).

Moreover, from the vaccine manufacturer's point of view, the expression and purification of a licensed single recombinant chimera vaccine including the two domains, would be easier to achieve and more economic, than the expression and isolation of each one of the domains individually (12).

In order to check these possibilities we compared the prophylactic efficacy of the NH36, F1, F3, admixed F1+F3 domains and the F1F3 recombinant chimera in mice, against the infection L. (L.) amazonensis (12).

While the chimera promoted the highest anti-NH36 antibody levels, and the strongest DTH and the highest secretions of IFN$\gamma$ and IL-10, the F3 vaccine induced the highest secretion of TNF- $\alpha$ (12). Furthermore, the chimera and the F1 vaccine also stimulated the increase of the frequencies of CD4+ and CD8 $+\mathrm{T}$ cells secreting IL-2, TNF- $\alpha$ or IFN- $\gamma$ alone, or any combination of two cytokines. In addition, the F1 and chimera vaccines enhanced the frequencies of the CD4+ multifunctional cells secreting IL-2, TNF- $\alpha$ and IFN- $\gamma$ simultaneously (12), which are the type of cell correlated with the desired Th1 memory response $(89,104)$. The admixed domains and the chimera reduced the skin lesions sizes by 80 and $84 \%$ respectively. In addition, the chimera generated the most pronounced and significant reduction of the parasite load $(99.8 \%)$. We concluded that the epitope presentation by the recombinant chimera F1F3 optimizes the immunogenicity and efficacy of the vaccine above the levels induced by the independent or admixed F1 and F3 domains (12). The chimera vaccine also induced a Th1-CD4 ${ }^{+} \mathrm{T}$ cell response that targeted the FRYPRPKHCHTQVA epitope of F3 and the YPPEFKTKL epitope of F1, which together with DVAGIVGVPVAAGCT, FMLQILDFYTKVYE and ELLAITTVVGNQ, also induced the strongest $\mathrm{CD}^{+} \mathrm{T}$ cell response and secretion of IL-10. Therefore, the YPPEFKTKL sequence might promote the $\mathrm{CD} 4^{+}, \mathrm{CD}^{+}$ $\mathrm{T}$ cell, and a potential $\mathrm{T}$ regulatory response. These results represented an important step toward the design of a nucleoside hydrolase NH36 based polytope vaccine for the generation of cross-protection against cutaneous leishmaniasis (12).

\section{TOWARD THE DESIGN OF A MULTI-EPITOPE HUMAN VACCINE AGAINST LEISHMANIASIS}

The results disclosed by our investigations about the potential use of the NH36 antigen in diagnosis and vaccination against leishmaniasis $(5,9-12,53,56,77,98-101)$ has inspired the work of other groups, which have used the NH36 recombinant protein for the development of a formulation against human visceral leishmaniasis $(15,94,95)$. The whole NH36 of $L$. (L.) donovani and the sterol 24-c-methyltransferase (SMT) from L. (L.) infantum were expressed as a fusion protein called LeishF3 that is being tested in clinical trials $(15,105)$. When formulated with glucopyranosyl lipid A-stable oil-in-water nanoemulsion (GLA$\mathrm{SE}$ ), a Toll-like receptor $4 \mathrm{TH} 1$ (T helper 1), the Leish+F3 protein protected mice against $L$. (L.) donovani and $L$. (L.) infantum infections, showing multifunctional CD4 T cells secreting IFN- $\gamma$, TNF- $\alpha$ and IL- 2 with low levels of IL-5 and IL-10. This protection was mediated by $\mathrm{CD} 4^{+}$but not by $\mathrm{CD} 8^{+} \mathrm{T}$ cells $(15)$. These results confirmed our previous data obtained after vaccination with the NH36 antigen in mice $(9,24)$ and dogs $(101)$. In fact, the NH36 vaccine induced protection against $L$. (L.) infantum chagasi, which was depleted with the treatment with anti-CD4 ${ }^{+}$ antibody (9).

Furthermore, a phase 1 clinical study with LeishF3 + GLA-SE was performed in healthy, uninfected adults in the United States. LeishF3, with or without the GLA-SE adjuvant, was tested in 36 healthy adults volunteers (15). The vaccine was immunogenic and well-tolerated. Only tenderness and/or pain at the injection site, fatigue and decreased hemoglobin were reported as adverse effects. As expected for the use of an adjuvant that contains QS21 saponin, an increased $\mathrm{TH} 1$ and $\mathrm{TH} 2$ cytokine response was observed in individuals that received LeishF3+GLA-SE. The vaccine was immunogenic when administered with adjuvant and increased mainly the IgG1 and IgG3 antigen-specific subtypes of antibodies in serum. In addition, the secretion of IFN- $\gamma$, TNF- $\alpha$, IL-2, IL-5, and IL-10 in response to Leish+F3 was enhanced in 
vaccinated subjects. However, this was followed by a decrease in IL-10 and IL-5 levels and sustained levels of IL-2 (against NH36 and SMT) and TNF- $\alpha$ (against NH36) $(15,104)$. These results confirm our previous descriptions of the induction of strong IL2 and TNF- $\alpha$ antigen specific responses in mice vaccinated with NH36 and its domains $(9-12,106)$ and in human asymptomatic $\mathrm{DTH}+$ and cured individuals infected with $L$. (L.) infantum chagasi of Brazil (13) and L. (L.) infantum of Spain (14).

We demonstrated, in the mice model, that the efficacy of the NH36 vaccine can be optimized by using the correct mixture of domains and epitopes (9-12). In the development of a multi-epitope vaccine destined to protect against cutaneous and visceral human leishmaniasis, two priorities should be taken into consideration. The selected epitopes and domains should be conserved among the different Leishmania species (13), and the epitopes should be highly promiscuous and bind to as many allotypes of HLA DR, DQ and DP MHC Class II, and of HLA A and B MHC Class I histocompatibility genes and T cell clones as possible (97).

Aiming to identify the main domains and epitopes of NH36 that deserve to be included in an optimized vaccine, we recently assessed in cured and active patients of visceral leishmaniasis and in asymptomatic infected subjects from Brazil their cytokine secretion, in response to NH36 and its domains, and their clinical symptoms (13). The F2 and F1 domains constituted markers of resistance to $\mathrm{VL}$, since together they promoted the highest secretion of IL-17, IL-6 and IL-10 in asymptomatic $\mathrm{DTH}^{+}$ individuals. In addition, F2 also provoked the strongest secretion of IFN- $\gamma$, TNF- $\alpha$ and IL- $1 \beta$ and the highest proportions of CD $4^{+}$ $\mathrm{T}$ cells secreting IL- $2^{+}$, IL- $2^{+} \mathrm{TNF}-\alpha^{+}$, IL- $2^{+} \mathrm{IFN}-\gamma^{+}$and IL$2^{+}$TNF- $\alpha^{+}$IFN- $\alpha^{+}$, both in cured and asymptomatic subjects. In agreement, in response to $\mathrm{F} 1$, the IFN- $\gamma$ increase was correlated with decreased sizes of liver and spleen and with increased hematocrit counts. Moreover, in response to the F2 domain, the IFN- $\gamma$ increase was associated to an increased hematocrit and hemoglobin counts (13). Furthermore, the enhancements in IL17 secretion correlated also with decreased spleen and liver sizes in response to $\mathrm{F} 1$ and $\mathrm{F} 2$.

In contrast, the F1 and F3 domains amplified the frequencies of $\mathrm{CD}^{+}{ }^{+} \mathrm{T}$ cells secreting IL- $2^{+}$, IL- $2^{+} \mathrm{TNF}-\alpha^{+}$, and IL- $2^{+} \mathrm{TNF}-$ $\alpha^{+}$IFN- $\gamma^{+}$of patients with active VL, in association with the enlargement of spleen and liver sizes, and decreased hematocrit and hemoglobin counts. We concluded that the cure and acquired resistance to $\mathrm{VL}$ is associated to the $\mathrm{CD} 4^{+} \mathrm{Th} 1$ and Th17 T-cell responses to the F2 and F1 domains. In contrast, clinical signs of $\mathrm{VL}$ correlate to $\mathrm{CD}^{+} \mathrm{T}$-cell responses against $\mathrm{F} 3$ and F1. In agreement with our experimental results, the initial in silico prediction with the TEPITOPE software disclosed one epitope in F1 and two epitopes in F2 that bind to at least 19 of 25 HLA-DR allotypes of MHC Class II molecules. In addition, five epitopes for $\mathrm{CD}^{+} \mathrm{T}$ cells were disclosed in $\mathrm{F} 1$ and $\mathrm{F} 3$ by the SYFPEITHI software. These epitopes bind to at least 17 HLA-A and B allotypes (13). All these epitopes were highly conserved in species of the Leishmania subgenus, and showed minor variations in the Viannae subgenus. The in silico predictions were confirmed since the three synthetic epitopes predicted for the $\mathrm{CD}^{+} \mathrm{T}$ cells in F1 and F2 as well as two epitopes of F1, predicted for $\mathrm{CD}^{+}$ $\mathrm{T}$ cells stimulated a significant secretion of IFN- $\gamma$ by PBMC in asymptomatic $\mathrm{DTH}^{+}$L. (L.) infantum chagasi infected subjects. Since no human vaccine against Leishmania is available so far, our results indicate that the identified domains and epitopes of NH36 could be used in combination to optimize a universal multi-epitope vaccine against leishmaniasis (13).

In addition, the antigenicity of the NH36 domains was tested on L. (L.) infantum infected subjects from Spain (14). The F1 induced a $19 \%$ stronger PBMC proliferative response than NH36, in asymptomatic infected subjects. Moreover, F1 promoted a $42-43 \%$ higher IFN- $\gamma$ and TNF- $\alpha$ secretion in cured subjects. In addition, higher IL-17 secretion was promoted by the F1 in asymptomatic subjects, and by NH36 in cured cutaneous leishmaniasis patients. Furthermore, as predicted in silico, a Granzyme B increase was detected in supernatants from cured patients after stimulation with either NH36 or F1 $[13,14]$.

Regarding the antibody response, $\mathrm{F} 1$ and NH36 differentiated the IgG3 response in $L$. (L.) donovani patients with VL from Ethiopia and L. (L.) infantum patients from Spain. In contrast, NH36 recognized with higher titers the sera from $L$. (L.) donovani-infected individuals from Ethiopia, suggesting speciesspecificity. Therefore, the F1 domain, which induced a Th1 and Th17 response in cured and $\mathrm{DTH}^{+}$L. (L.) infantum chagasi infected subjects, may also promote a protective immune response against Leishmania (L.) infantum (14).

\section{CONCLUSIONS}

Nucleoside hydrolases are vital enzymes for the replication of Leishmania, conserved phylogenetic marker of the genus and strong-specific immunogens. We demonstrated that NH36 is an excellent target for chemotherapy of visceral leishmaniasis. Searching for the most immunogenic fraction of promastigotes of Leishmania we described the FML antigen of L. (L.) donovani, that has as its main component, the NH36 Nucleoside hydrolase. We developed second-generation vaccines with the FML and the NH36 native antigens, and with the NH36 recombinant protein. In addition, we obtained a third generation vaccine based upon the NH36 gene. All these vaccines were protective and curative when assayed in the murine and canine models of leishmaniasis, and the FML-vaccine called Leishmune ${ }^{\circledR}$ reduced the incidence of human and canine disease in the endemic areas. Recently we initiate the search for the most immunogenic part of the NH36 sequence aiming to optimize the vaccine efficacy. We observed that the $\mathrm{F} 3$ vaccine has an important role in signaling the optimal control of visceral leishmaniasis in mice and that the F1 domain is also needed for protection against tegumentary leishmaniasis. This knowledge allowed us to develop a recombinant chimera vaccine, which optimized the vaccine efficacy. Furthermore, aiming to develop a potential T-cell epitope synthetic vaccine against both human visceral and cutaneous leishmaniasis we identified the major immunogenic regions of NH36 recognized by PBMCs of cured and asymptomatic patients infected with $L$. (L.) infantum chagasi in Brazil and L. (L.) infantum in Spain and L. (L.) donovani in Ethiopia. In each step of our investigation the vaccine formulation including $\mathrm{NH} 36$ and its domains gained in efficacy and safety. Once all the major HLA DR, DQ and DP and HLA-A and B promiscuous epitopes of NH36 have been 
identified, the design of a multi-epitope vaccine for prevention of human visceral and cutaneous leishmaniasis will be completed.

\section{AUTHOR CONTRIBUTIONS}

The author confirms being the sole contributor of this work and has approved it for publication.

\section{FUNDING}

This work was supported by: Conselho Nacional de Desenvolvimento Científico e Tecnológico (CNPQ) fellowship

\section{REFERENCES}

1. Lukes J, Mauricio IL, Schonian G, Dujardin JC, Soteriadou K, Dedet JP, et al. Evolutionary and geographical history of the Leishmania donovani complex with a revision of current taxonomy. Proc Natl Acad Sci USA. (2007) 104:9375-80. doi: 10.1073/pnas.0703678104

2. Mauricio IL, Yeo M, Baghaei M, Doto D, Pratlong F. Towards multilocus sequence typing of the Leishmania donovani complex: resolving genotypes and haplotypes for five polymorphic metabolic enzymes (ASAT, GPI, NH1, NH2, PGD). Int J Parasitol. (2006) 36:757-69. doi: 10.1016/j.jpara.2006.03.006

3. Versées W, Goeminne A, Berg M, Vandemeulebroucke A, Haemers A, Augustyns K. Crystal structures of T. vivax nucleoside hydrolase in complex with new potent and specific inhibitors. Biochim Biophys Acta. (2009) 1794:953-60. doi: 10.1016/j.bbapap.2009.02.011

4. Iovane E, Giabbai B, Muzzolini L, Matafora V, Fornili A, Minici C. Structural basis for substrate specificity in group I nucleoside hydrolases. Biochemistry. (2008) 47:4418-26. doi: 10.1021/bi702448s

5. Freitas EO, Nico D, Guan R, Meyer-Fernandes JR, Clinch K, Evans GB, et al. Immucillins Impair Leishmania (L.) infantum chagasi and Leishmania (L.) amazonensis multiplication In Vitro. PLoS ONE. (2015) 10:e0124183. doi: 10.1371/journal.pone.0124183

6. Freitas EO, Nico D, Alves-Silva MV, Morrot A, Clinch K, Evans GB, et al. Immucillins ImmA and ImmH are effective and non-toxic in the treatment of experimental visceral leishmaniasis. PLoS Negl Trop Dis. (2015) 9:e0004297. doi: 10.1371/journal.pntd.0004297

7. Figueroa-Villar JD, Sales EM. The importance of nucleoside hydrolase enzyme $(\mathrm{NH})$ in studies to treatment of Leishmania: a review. Chem Biol Interact. (2017) 263:18-27. doi: 10.1016/j.cbi.2016.12.004

8. Karami M, Jalali C, Mirzaie S. Combined virtual screening, MMPBSA, molecular docking and dynamics studies against deadly anthrax: an in silico effort to inhibit Bacillus anthracis nucleoside hydrolase. J Theor Biol. (2017) 420:180-9. doi: 10.1016/j.jtbi.2017.03.010

9. Nico D, Claser C, Borja-Cabrera GP, Travassos LR, Palatnik M, Soares IS, et al. Adaptive immunity against Leishmania nucleoside hydrolase maps its c-terminal domain as the target of the CD4+ T cell-driven protective response. PLoS Negl Trop Dis. (2010) 4:e866. doi: 10.1371/journal.pntd.0000866

10. Nico D, Gomes DC, Alves-Silva MV, Freitas EO, Morrot A, Bahia $\mathrm{D}$, et al. Cross-protective immunity to Leishmania amazonensis is mediated by $\mathrm{CD} 4+$ and $\mathrm{CD} 8+$ epitopes of Leishmania donovani nucleoside hydrolase terminal domains. Front Immunol. (2014) 5:189. doi: 10.3389/fimmu.2014.00189

11. Nico D, Gomes DC, Palatnik-de-Sousa I, Morrot A, Palatnik M, Palatnikde-Sousa CB. Leishmania donovani nucleoside hydrolase terminal domains in cross-protective immunotherapy against Leishmania amazonensis murine infection. Front Immunol. (2014) 5:273. doi: 10.3389/fimmu.2014. 00273

12. Alves-Silva MV, Nico D, Morrot A, Palatnik M, Palatnik-de-Sousa CB. A chimera containing CD4+ and CD8+ T-cell epitopes of the
310977/2014-2, 304764/2018-3, and grant 404400/ 2012-4; and by Fundação Carlos Chagas de Amparo à Pesquisa do Estado de Rio de Janeiro (FAPERJ) grants E-26-201.583/2014, E-26/ 111.682/2013 (to CP-d-S). Additionally, this study was financed in part by the Coordenação de Aperfeiçoamento de Pessoal de Nível Superior-Brasil (CAPES)-Finance Code 001 .

\section{ACKNOWLEDGMENTS}

The author thanks David Straker for English review of this manuscript.

Leishmania donovani nucleoside hydrolase (NH36) optimizes crossprotection against Leishmania amazonesis Infection. Front Immunol. (2017) 8:100. doi: 10.3389/fimmu.2017.00100

13. Barbosa Santos ML, Nico D, de Oliveira FA, Barreto AS, Palatnik-de-Sousa I, Carrillo E, et al. Leishmania donovani nucleoside hydrolase (NH36) domains induce T-cell cytokine responses in human visceral leishmaniasis. Front Immunol. (2017) 8:227. doi: 10.3389/fimmu.2017.00227

14. Carrillo E, Fernandez L, Ibarra-Meneses AV, Santos MLB, Nico D, de Luca PM, et al. F1 domain of the Leishmania (Leishmania) donovani nucleoside hydrolase promotes a Th1 response in Leishmania (Leishmania) infantum cured patients and in asymptomatic individuals living in an endemic area of leishmaniasis. Front Immunol. (2017) 8:750. doi: 10.3389/fimmu.2017.00750

15. Coler RN, Duthie MS, Hofmeyer KA, Guderian J, Jayashankar L, Vergara J, et al. From mouse to man: safety, immunogenicity and efficacy of a candidate leishmaniasis vaccine LEISH-F3+GLA-SE. Clin Transl Immunol. (2015) 4:e35. doi: 10.1038/cti.2015.6

16. Todd SJ, Moir AJ, Johnson MJ, Moir A. Genes of Bacillus cereus and Bacillus anthracis encoding proteins of the exosporium. J Bacteriol. (2003) 185:3373-78. doi: 10.1128/JB.185.11.3373-3378.2003

17. Borja-Cabrera GP, Santos FN, Bauer FS, Parra LE, Menz I, Morgado $\mathrm{AA}$, et al. Immunogenicity assay of the Leishmune vaccine against canine visceral leishmaniasis in Brazil. Vaccine. (2008) 26:4991-7. doi: 10.1016/j.vaccine.2008.07.029

18. Parra LE, Borja-Cabrera GP, Santos FN, Souza LO, Palatnik-deSousa $\mathrm{CB}$, Menz I. Safety trial using the Leishmune vaccine against canine visceral leishmaniasis in Brazil. Vaccine. (2007) 25:2180-6. doi: 10.1016/j.vaccine.2006.11.057

19. Nogueira FS, Moreira MA, Borja-Cabrera GP, Santos FN, Menz I, Parra LE, et al. Leishmune vaccine blocks the transmission of canine visceral leishmaniasis: absence of Leishmania parasites in blood, skin and lymph nodes of vaccinated exposed dogs. Vaccine. (2005) 23:4805-10. doi: 10.1016/j.vaccine.2005.05.011

20. Saraiva EM, de Figueiredo Barbosa A, Santos FN, Borja-Cabrera GP, Nico $\mathrm{D}$, Souza LO, et al. The FML-vaccine (Leishmune) against canine visceral leishmaniasis: a transmission blocking vaccine. Vaccine. (2006) 24:2423-31. doi: 10.1016/j.vaccine.2005.11.061

21. Palatnik-de-Sousa CB, Barbosa A de F, Oliveira SM, Nico D, Bernardo RR, Santos WR, et al. FML vaccine against canine visceral leishmaniasis: from second-generation to synthetic vaccine. Exp Rev Vaccines. (2008) 7:833-51. doi: 10.1586/14760584.7.6.833

22. Palatnik-de-Sousa CB, Silva-Antunes I, Morgado A de A, Menz I, Palatnik $\mathrm{M}$, Lavor C. Decrease of the incidence of human and canine visceral leishmaniasis after dog vaccination with Leishmune in Brazilian endemic areas. Vaccine. (2009) 27:3505-12. doi: 10.1016/j.vaccine.2009.03.045

23. Santana DM, Borja-Cabrera GP, Paraguai de Souza E, Sturm NR, Palatnik de Sousa CB, Campbell DA. Nucleoside hydrolase from Leishmania (L.) donovani is an antigen diagnostic for visceral leishmaniasis. Mol Biochem Parasitol. (2002) 120:315-9.

24. Aguilar-Be I, da Silva Zardo R, Paraguai de Souza E, Borja-Cabrera GP, Rosado-Vallado M, Mut-Martin M, et al. Cross-protective efficacy 
of a prophylactic Leishmania donovani DNA vaccine against visceral and cutaneous murine leishmaniasis. Infect Immun. (2005) 73:812-9. doi: 10.1128/IAI.73.2.812-819.2005

25. Baresova V, Skopova V, Souckova O, Krijt M, Kmoch S, Zikanova M. Study of purinosome assembly in cell-based model systems with de novo purine synthesis and salvage pathway deficiencies. PLOS ONE. (2018) 13:e0201432. doi: 10.1371/journal.pone.0201432

26. Cassera MB, Hazleton KZ, Merino EF, Obaldia N 3rd, Ho MC, Murkin AS, et al. Plasmodium falciparum parasites are killed by a transition state analogue of purine nucleoside phosphorylase in a primate animal model. PLoS ONE. (2011) 6:e26916. doi: 10.1371/journal.pone.0026916

27. Reyes P, Rathod PK, Sanchez DJ, Mrema JE, Rieckmann KH, Heidrich HG. Enzymes of purine and pyrimidine metabolism from the human malaria parasite, Plasmodium falciparum. Mol Biochem Parasitol. (1982) 5:275-90.

28. Lo HS, Wang CC. Purine salvage in Entamoeba histolytica. J Parasitol. (1985) 71:662-9.

29. Hassan HF, Coombs GH. Purine-metabolising enzymes in Entamoeba histolytica. Mol Biochem Parasitol. (1986) 19:19-26.

30. Sarver AE, Wang CC. The adenine phosphoribosyltransferase from Giardia lamblia has a unique reaction mechanism and unusual substrate binding properties. J Biol Chem. (2002) 277:39973-80. doi: 10.1074/jbc.M205595200

31. Krug EC, Marr JJ, Berens RL. Purine metabolism in Toxoplasma gondii. J Biol Chem. (1989) 264:10601-7.

32. Donaldson TM, Cassera MB, Ho MC, Zhan C, Merino EF, Evans GB, et al. Inhibition and structure of Toxoplasma gondii purine nucleosyde phophorylase. Eukaryot Cell. (2014) 13:572-9. doi: 10.1128/EC.00308-13

33. Evans GB, Tyler PC, Schramm VL. Immucillins in infectious diseases. Infect Dis. (2018) 4:107-17. doi: 10.1021/acsinfecdis.7b00172

34. Campagnaro GD, de Freitas Nascimento J, Girard RBM, Silber AM, de Koning HP. Cloning and characterisation of the equilibrative nucleoside transporter family of Trypanosoma cruzi: ultra-high affinity and selectivity to survive in the intracellular niche. Biochim Biophys Acta Gen Subj. (2018) 1862:2750-63. doi: 10.1016/j.bbagen.2018.08.015

35. DoleŽelová E, Terán D, Gahura O, Kotrbová Z, Procházková M, Keough D, et al. Evaluation of the Trypanosoma brucei 6-oxopurine salvage pathway as a potential target for drug discovery. PLoS Negl Trop Dis. (2018) 12:e0006301. doi: 10.1371/journal.pntd.0006301

36. Parkin DW. Purine-specific nucleoside N-ribohydrolase from Trypanosoma brucei brucei. Purification, specificity, and kinetic mechanism. J Biol Chem. (1996) 271:21713-9.

37. Giannese F, Berg M, Van der Veken P, Castagna V, Tornaghi P, Augustyns $\mathrm{K}$, et al. Structures of purine nucleosidase from Trypanosoma brucei bound to isozyme-specific trypanocidals and a novel metalorganic inhibitor. Acta Crystallogr D Biol Crystallogr. (2013) 69:1553-66. doi: $10.1107 /$ S0907444913010792

38. Marr JJ, Berens RL, Nelson DJ. Purine metabolism in Leishmania donovani and Leishmania braziliensis. Biochem Biophys Acta. (1978) 544: 360-71.

39. Shi W, Schramm VL, Almo SC. Nucleoside hydrolase from Leishmania major. Cloning, expression, catalytic properties, transition state inhibitors, and the 2.5-å crystal structure. J Biol Chem. (1999) 274:21114-20.

40. Freitas-Mesquita AL, Meyer-Fernandes JR. 3'nucleotidase/nuclease in protozoan parasites: molecular and biochemical properties and physiological roles. Exp Parasitol. (2017) 179:1-6. doi: 10.1016/j.exppara.2017.06.001

41. Liu W, Boitz JM, Galazka J, Arendt CS, Carter NS, Ullman B. Functional characterization of nucleoside transporter gene replacements in Leishmania donovani. Mol Biochem Parasitol. (2006) 150:300-7. doi: 10.1016/j.molbiopara.2006.09.002

42. Carter NS, Yates P, Arendt CS, Boitz JM, Ullman B. Purine and pyrimidine metabolism in Leishmania. Adv Exp Med Biol. (2008) 625:14154. doi: 10.1007/978-0-387-77570-8_12

43. Cui L, Rajasekariah GR, Martin SK. A nonspecific nucleoside hydrolase from Leishmania donovani: implications for purine salvage by the parasite. Gene. (2001) 280:153-62. doi: 10.1016/S0378-1119(01)00768-5

44. Blast-Basic Local Alignment SearchTool. National Institute of Health (NIH) (2014). Available online at: http://blast.ncbi.nlm.nih.gov/Blast.cgi (accessed march 15, 2019).

45. Clinch K, Evans GB, Fröhlich RF, Furneaux RH, Kelly PM, Legentil L. Thirdgeneration immucillins: syntheses and bioactivities of acyclic immucillin inhibitors of human purine nucleoside phosphorylase. J Med Chem. (2009) 52:1126-43. doi: 10.1021/jm801421q

46. Martin JL, Yates PA, Soysa R, Alfaro JF, Yang F, Burnum-Johnson $\mathrm{KE}$, et al. Metabolic reprogramming during purine stress in the protozoan pathogen Leishmania donovani. PLoS Pathog. (2014) 10:e1003938. doi: 10.1371/journal.ppat.1003938

47. Alvar J, Vélez ID, Bern C, Herrero M, Desjeux P, Cano J, et al. Leishmaniasis worldwide and global estimates of its incidence. PLoS ONE. (2012) 7:e35671. doi: 10.1371/journal.pone.0035671

48. Palatnik-de-Sousa CB, Day MJ. One Health: the global challenge of epidemic and endemic leishmaniasis. Parasit Vectors. (2011) 4:197. doi: 10.1186/1756-3305-4-197

49. Regina-Silva S, Feres AM, França-Silva JC, Dias ES, Michalsky ÉM, de Andrade HM, et al. Field randomized trial to evaluate the efficacy of the Leish-Tec ${ }^{\circledR}$ vaccine against canine visceral leishmaniasis in an endemic area of Brazil. Vaccine. (2016) 34:2233-9. doi: 10.1016/j.vaccine.2016.03.019

50. Oliva G, Nieto J, Foglia Manzillo V, Cappiello S, Fiorentino E, Di Muccio $\mathrm{T}$, et al. A randomised, double-blind, controlled efficacy trial of the LiESP/QA-21 vaccine in naïve dogs exposed to two Leishmania infantum transmission seasons. PLoS Negl Trop Dis. (2014) 8:e3213. doi: 10.1371/journal.pntd.0003213

51. Carcelén J1, Iniesta V, Fernández-Cotrina J, Serrano F, Parejo JC, Corraliza I, et al. The chimerical multi-component $\mathrm{Q}$ protein from Leishmania in the absence of adjuvant protects dogs against an experimental Leishmania infantum infection. Vaccine. (2009) 27:5964-73. doi: 10.1016/j.vaccine.2009.07.069

52. Palatnik CB, Borojevic R, Previato JO, Mendonça-Previato L. Inhibition of Leishmania donovani promastigote internalization into murine macrophages by chemically defined parasite glycoconjugate ligands. Infect Immun. (1989) 57:754-63.

53. Palatnik-de-Sousa CB, Dutra HS, Borojevic R. Leishmania donovani surface glycoconjugate GP36 is the major immunogen component of the fucosemannose ligand (FML). Acta Trop. (1993) 53:59-72.

54. Palatnik CB, Previato JO, Mendonça-Previato L, Borojevic R. A new approach to the phylogeny of Leishmania: species specificity of glycoconjugate ligands for promastigote internalization into murine macrophages. Parasitol Res. (1990) 76:289-93.

55. Palatnik-de-Sousa CB, Gomes EM, Paraguai-de-Souza E, Palatnik M, Luz K, Borojevic R. Leishmania donovani: titration of antibodies to the fucose-mannose ligand as an aid in diagnosis and prognosis of visceral leishmaniasis. Trans R Soc Trop Med Hyg. (1995) 89:390-3.

56. Cabrera GP, Da Silva VO, Da Costa RT, Reis AB, Mayrink W, Genaro O, et al. The fucose-mannose ligand-ELISA in the diagnosis and prognosis of canine visceral leishmaniasis in Brazil. Am J Trop Med Hyg. (1999) 61:296-301.

57. Luz KG, da Silva VO, Gomes EM, Machado FC, Araujo MA, Fonseca HE, et al. Prevalence of anti-Leishmania donovani antibody among Brazilian blood donors and multiply transfused hemodialysis patients. Am J Trop Med Hyg. (1997) 57:168-71.

58. Paraguai de Souza E, Bernardo RR, Palatnik M, Palatnik de Sousa CB. Vaccination of Balb/c mice against experimental visceral leishmaniasis with the GP36 glycoprotein antigen of Leishmania donovani. Vaccine. (2001) 19:3104-15. doi: 10.1016/S0264-410X(01)00031-7

59. Palatnik-de-Sousa CB, Paraguai-de-Souza E, Gomes EM, Borojevic R. Experimental murine Leishmania donovani infection: immunoprotection by the fucose-mannose ligand (FML). Braz J Med Biol Res. (1994) 27:547-51.

60. Palatnik de Sousa CB, Bunn Moreno MM, Paraguai de Souza E, Borojevic R. Vaccination with the FML antigen (Fucose Mannose Ligand) of Leishmania donovani protects hamsters from experimental Viceral Leishmaniasis. J Braz Soc Adv Sci Ciência e Cultura. (1994) 46:290-6.

61. Santos WR, de Lima VM, de Souza EP, Bernardo RR, Palatnik M, Palatnik de Sousa CB. Saponins, IL12 and BCG adjuvant in the FML-vaccine formulation against murine visceral leishmaniasis. Vaccine. (2002) 21:30-43.

62. Oliveira-Freitas E, Casas CP, Borja-Cabrera GP, Santos FN, Nico D, Souza $\mathrm{LO}$, et al. Acylated and deacylated saponins of Quillaja saponaria mixture as adjuvants for the FML-vaccine against visceral leishmaniasis. Vaccine. (2006) 24:3909-20. doi: 10.1016/j.vaccine.2006.02.034

63. da Silva VO, Borja-Cabrera GP, Correia Pontes NN, de Souza EP, Luz KG, Palatnik M, et al. A phase III trial of efficacy of the FML-vaccine against 
canine kala-azar in an endemic area of Brazil (São Gonçalo do Amaranto, RN). Vaccine. (2000) 19:1082-92.

64. Borja-Cabrera GP, Correia Pontes NN, da Silva VO, Paraguai de Souza E, Santos WR, Gomes EM, et al. Long lasting protection against canine kala-azar using the FML-QuilA saponin vaccine in an endemic area of Brazil (São Gonçalo do Amarante, RN). Vaccine. (2002) 20:3277-84. doi: 10.1016/S0264-410X(02)00294-3

65. de Oliveira Mendes C, Paraguai de Souza E, Borja-Cabrera GP, Batista MML, dos Santos MA, Parra LE, et al. IgG1/IgG2 antibody dichotomy in sera of vaccinated or naturally infected dogs with visceral leishmaniosis. Vaccine. (2003) 21:2589-97.

66. Borja-Cabrera GP, Cruz Mendes A, Paraguai de Souza E, Hashimoto Okada LY, de A Trivellato FA, et al. Effective immunotherapy against canine visceral leishmaniasis with the FML-vaccine. Vaccine. (2004) 22:2234-43. doi: 10.1016/j.vaccine.2003.11.039

67. Santos FN, Borja-Cabrera GP, Miyashiro LM, Grechi J, Reis AB, Moreira MA, et al. Immunotherapy against experimental canine visceral leishmaniasis with the saponin enriched-Leishmune vaccine. Vaccine. (2007) 25:6176-90. doi: 10.1016/j.vaccine.2007.06.005

68. Borja-Cabrera GP, Santos FN, Santos FB, Trivellato FA, Kawasaki $\mathrm{JK}$, Costa AC, et al. Immunotherapy with the saponin enrichedLeishmune vaccine versus immunochemotherapy in dogs with natural canine visceral leishmaniasis. Vaccine. (2010) 28:597-603. doi: 10.1016/j.vaccine.2009.09.071

69. de Mendonça LZ, Resende LA, Lanna MF, Aguiar-Soares RD, Roatt BM, Castro RA, et al. Multicomponent LBSap vaccine displays immunological and parasitological profiles similar to those of Leish-Tec ${ }^{\circledR}$ and Leishmune ${ }^{\circledR}$ vaccines against visceral leishmaniasis. Parasit Vectors. (2016) 9:472. doi: 10.1186/s13071-016-1752-6

70. Fernandes CB, Junior JT, de Jesus C, Souza BM, Larangeira DF, Fraga $\mathrm{DB}$, et al. Comparison of two commercial vaccines against visceral leishmaniasis in dogs from endemic areas: $\operatorname{IgG}$, and subclasses, parasitism, and parasite transmission by xenodiagnosis. Vaccine. (2014) 32:1287-95. doi: 10.1016/j.vaccine.2013.12.046

71. Moreira ML, Costa-Pereira C, Alves ML, Marteleto BH, Ribeiro VM, Peruhype-Magalhães V, et al. Vaccination against canine leishmaniosis increases the phagocytic activity, nitric oxideproduction and expression of cell activation/migration molecules in neutrophils and monocytes. Vet Parasitol. (2016) 220:33-45. doi: 10.1016/j.vetpar.2016.02.009

72. Costa-Pereira C, Moreira ML, Soares RP, Marteleto BH, Ribeiro VM, FrançaDias $\mathrm{MH}$, et al. One-year timeline kinetics of cytokine-mediated cellular immunity in dogs vaccinated against visceral leishmaniasis. BMC Vet Res. (2015) 11:92. doi: 10.1186/s12917-015-0397-6

73. de Lima VM, Ikeda FA, Rossi CN, Feitosa MM, Vasconcelos RO, Nunes $\mathrm{CM}$, et al. Diminished CD4+/CD25+ T cell and increased IFN-gamma levels occur in dogs vaccinated with Leishmune in an endemic area for visceral leishmaniasis. Vet Immunol Immunopathol. (2010) 135:296-302. doi: 10.1016/j.vetimm.2009.12.008

74. Araújo MS, de Andrade RA, Sathler-Avelar R, Teixeira-Carvalho A, Andrade MC, Vianna LR, et al. T-cell-derived cytokines, nitric oxide production by peripheral blood monocytes and seric anti-Leishmania (Leishmania) chagasi IgG subclass patterns following immunization against canine visceral leishmaniasis using Leishvaccine and Leishmune. Vaccine. (2009) 27:100817. doi: $10.1016 /$ j.vaccine.2008.11.104

75. Marciani DJ. Vaccine adjuvants: role and mechanisms of action in vaccine immunogenicity. Drug Discov Today. (2003) 8:934-43.

76. Dye C. The logic of visceral leishmaniasis control. Am J Trop Med Hyg. (1996) 55:125-30.

77. Palatnik de Sousa CB, Gomes EM, de Souza EP, dos Santos WR, de Macedo SR, de Medeiros LV, et al. The FML (Fucose Mannose Ligand) of Leishmania donovani. a new tool in diagnosis, prognosis, transfusional control and vaccination against human kala-azar. Rev Soc Bras Med Trop. (1996) 29:15363.

78. Coelho EA, Tavares CA, Carvalho FA, Chaves KF, Teixeira KN, Rodrigues RC. Immune responses induced by the Leishmania (Leishmania) donovani A2 antigen, but not by the LACK antigen, are protective against experimental Leishmania (Leishmania) amazonensis infection. Infect Immun. (2003) 71:3988-94.
79. Ghosh A, Labrecque S, Matlashewski G. Protection against Leishmania donovani infection by DNA vaccination: increased DNA vaccination efficiency through inhibiting the cellular p53 response. Vaccine. (2001) 19:3169-78.

80. Ghosh A, Zhang WW, Matlashewski G. Immunization with A2 protein results in a mixed Th1/Th2 and a humoral response which protects mice against Leishmania donovani infections. Vaccine. (2001) 20:59-66.

81. Grimaldi G Jr., Teva A, Porrozzi R, Pinto MA, Marchevsky RS, Rocha MG, et al. Clinical and parasitological protection in a Leishmania infantum - macaque model vaccinated with adenovirus and the recombinant A2 antigen. PLoS Negl Trop Dis. (2014) 8:e2853. doi: 10.1371/journal.pntd.0002853

82. Fernandes AP, Costa MM, Coelho EA, Michalick MS, de Freitas E, Melo MN, et al. Protective immunity against challenge with Leishmania (Leishmania) chagasi in beagle dogs vaccinated with recombinant A2 protein. Vaccine. (2008) 26:5888-95. doi: 10.1016/j.vaccine.2008.05.095

83. Grimaldi G Jr., Teva A, Dos-Santos CB, Santos FN, Pinto ID, Fux B, et al. Field trial of efficacy of the Leish-tec ${ }^{\circledR}$ vaccine against canine leishmaniasis caused by Leishmania infantum in an endemic area with high transmission rates. PLoS ONE. (2017) 12:e0185438. doi: 10.1371/journal.pone.0185438

84. Fernández Cotrina J, Iniesta V, Monroy I, Baz V, Hugnet C, Marañon F, et al. A large-scale field randomized trial demonstrates safety and efficacy of the vaccine LetiFend ${ }^{\circledR}$ against canine leishmaniosis. Vaccine. (2018) 36:1972-82. doi: 10.1016/j.vaccine.2018.02.111

85. Gradoni L. Canine Leishmania vaccines: still a long way to go. Vet Parasitol. (2015) 208:94-100. doi: 10.1016/j.vetpar.2015.01.003

86. Rodrigues V, Cordeiro-da-Silva A, Laforge M, Silvestre R, Estaquier J. Regulation of immunity during visceral Leishmania infection. Parasit Vectors. (2016) 9:118. doi: 10.1186/s13071-016-1412-x

87. Hofmeyer KA, Duthie MS, Laurance JD, Favila MA, Van Hoeven N, Coler RN, et al. Optimizing immunization strategies for the induction of antigen specific CD4 and CD8 T cell responses for protection against intracellular parasites. Clin Vaccine Immunol. (2016) 23:785-94. doi: 10.1128/CVI.00251-16

88. Muller I, Pedrazzini T, Farrell JP, Louis J. T-cell responses and immunity to experimental infection with Leishmania major. Annu Rev Immunol. (1989) 7:561-78.

89. Darrah PA, Patel DT, De Luca PM, Lindsay RW, Davey DF, Flynn BJ, et al. Multifunctional TH1 cells define a correlate of vaccine-mediated protec-tion against Leishmania major. Nat Med. (2007) 13:843-50. doi: 10.1038/ nm1592

90. Singh OP, Stober CB, Singh AK, Blackwell JM, Sundar S. Cytokine responses to novel antigens in an Indian population living in an area endemic for visceral leishmaniasis. PLoS Negl Trop Dis. (2012) 6:e1874. doi: 10.1371/journal.pntd.0001874

91. Kumar R, Nylén S. Immunobiology of visceral leishmaniasis. Front Immunol. (2012) 3:251. doi: 10.3389/fimmu.2012.00251 9

92. Polley R, Stager S, Prickett S, Maroof A, Zubairi S, Smith DF, et al. Adoptive immunotherapy against experimental visceral leishmaniasis with CD8+ T cells requires the presence of cognate antigen. Infect Immun. (2006) 74:7736. doi: 10.1128/IAI.74.1.773-776.2006

93. Seyed N, Taheri T, Rafati S. Post-genomics and vaccine improvement for Leishmania. Front Microbiol. (2016) 7:467. doi: 10.3389/fmicb.2016.00467 15

94. McAtee CP, Seid CA, Hammond M, Hudspeth E, Keegan BP, Liu Z, et al. Expression, purification, immunogenicity and protective efficacy of a recombinant nucleoside hydrolase from Leishmania donovani, a vaccine candidate for preventing cutaneous leishmaniasis. Protein Expr Purif. (2017) 130:129-36. doi: 10.1016/j.pep.2016.10.008

95. Gillespie PM, Beaumier CM, Strych U, Hayward T, Hotez PJ, Bottazzi ME. Status of vaccine research and development of vaccines for leishmaniasis. Vaccine. (2016) 34:2992-5. doi: 10.1016/j.vaccine.2015.12.071

96. Murphy K. Imunobiologia de Janeway. 8th ed. Artmed Editora Ltd (2014).

97. Fleri W, Vaughan K, Salimi N, Vita R, Peters B, Sette A. The Immune epitope database: how data are entered and retrieved. J Immunol Res. (2017) 2017:5974574. doi: 10.1155/2017/5974574

98. Souza LOP, Palatnik de Sousa CB. The Nucleoside hydrolase DNA vaccine VR1012NH36 in prophylactic vaccination against mice tegumentar leishmaniaisis. Proc Vaccinol. (2009) 1:120-3. doi: $10.1016 /$ j.provac.2009.07.022 
99. Gamboa-León R, Paraguai de Souza E, Borja Cabrera GP, Santos FN, Miyashiro LM, Pinheiro RO, et al. Immunotherapy against visceral leishmaniasis with the nucleoside hydrolase-DNA vaccine of $L$. donovani. Vaccine. (2006) 24:4863-73. doi: 10.1016/j.vaccine.2006.03.005

100. Borja-Cabrera GP, Santos FB, Picillo E, Gravino E, Manna L, Palatnik-de-Sousa CB. Nucleoside hydrolase DNA vaccine against canine visceral leishmaniasis. Proc Vaccinol. (2009) 1: 104-9. doi: 10.1016/j.provac.2009.07.019

101. Borja-Cabrera GP, Santos FB, Nico D, Gravino AE, Manna L, Palatnik $\mathrm{M}$, et al. The leishmune ${ }^{\circledR}$ 's nucleoside hydrolase DNA vaccine as an aid in immunotherapy of canine visceral leishmaniasis. Proc Vaccinol. (2012) 6:64-73. doi: 10.1016/j.provac 2012.04.009

102. Jorge S, Dellagostin AO. The development of veterinary vaccines: a review of traditional methods and modern biotechnology approaches. Biotech Res Innov. (2017) 1:6-13. doi: 10.1016/j.biori.2017. 10.001

103. Kao DJ, Hodges RS. Advantages of a synthetic peptide immunogen over a protein immunogen in the development of an anti-pilus vaccine for Pseudomonas aeruginosa. Biol Drug Res. (2009) 74:33-42. doi: $10.1111 / j .1747-0285.2009 .00825$
104. Seder RA, Darrah PA, Roederer M. T cell quality in memory and protection: implications for vaccine design. Nature Rev. (2008) 8:247-58. doi: $10.1038 /$ nri2274

105. ClinicalTrials.gov. LEISH-F3 + GLA-SE and the LEISH-F3 + MPL-SE Vaccine (2015).

106. Nico D, Martins Almeida F, Motta JM, Cardoso SDS F, Freire-de-Lima CG, Freire-de-Lima L, et al. NH36 and F3 antigen-primed dendritic cells show preserved migrating capabilities and CCR7 expression and F3 is effective in immunotherapy of visceral leishmaniasis. Front Immunol. (2018) 9:967. doi: 10.3389/fimmu.2018.00967

Conflict of Interest Statement: CP-d-S is one of the inventors of the patent file PI1015788-3 (INPI Brazil) owned by the Federal University of Rio de Janeiro.

Copyright (c) 2019 Palatnik-de-Sousa. This is an open-access article distributed under the terms of the Creative Commons Attribution License (CC BY). The use, distribution or reproduction in other forums is permitted, provided the original author(s) and the copyright owner(s) are credited and that the original publication in this journal is cited, in accordance with accepted academic practice. No use, distribution or reproduction is permitted which does not comply with these terms. 